Article

\title{
Chemical Destabilization of Fresh and Spent Cutting Oil Emulsions: Differences between an Ecofriendly and Two Commercial Synthetic Lubricants
}

\author{
Danilo Spasiano $^{1, *(\mathbb{D})}$, Andrea Petrella ${ }^{1}$ and Vito Lacedra ${ }^{2}$ \\ 1 Department of Civil, Environmental, Land, Building Engineering and Chemistry, Polytechnic University of \\ Bari, Via E. Orabona, 4, 70125 Bari, Italy; andrea.petrella@poliba.it \\ 2 Dana Incorporated, Strada Provinciale Modugno-Bari, 4, 70132 Bari, Italy; vito.lacedra@dana.com \\ * Correspondence: danilo.spasiano@poliba.it; Tel.: +39-080-596-3240
}

Received: 8 June 2020; Accepted: 4 July 2020; Published: 15 July 2020

\begin{abstract}
The aim of this study was to evaluate if eco-friendly lubricants had an additional advantage over conventional synthetic lubricants in terms of emulsion treatment of metalworking wastewater. To these purpose, two fresh commercial synthetic cutting oil emulsions were compared with an emulsion obtained from a new cutting oil produced from the reuse of slaughtering waste (CADT-605 from Kimya Srl, Bari, Italy). The breaking of the fresh emulsions was carried out with the addition of small amounts of sulfuric acid $(2-20 \mathrm{~mL} / \mathrm{L})$ followed by $\mathrm{pH}$ neutralization by means of calcium hydroxide. During the two-step treatments, $\mathrm{COD}, \mathrm{BOD}_{5}$ and non-ionic surfactant (NIS) concentrations were monitored in the aqueous phase. The results demonstrated that the best results were obtained with the emulsion produced with the bio-based lubricant. In addition, this cutting oil was tested in a metalworking plant within 30 days and the resulting spent emulsion was treated with the proposed process. In all the cases, the treatment led to a drastic decrease of the COD, $\mathrm{BOD}_{5}$ and NIS contents that allow the discharge of resulting aqueous phase in sewers or in surface water bodies, together with the other wastewater produced by the plant, in agreement with the Italian regulation.
\end{abstract}

Keywords: emulsion breaking; surfactants; $\mathrm{COD}$; $\mathrm{BOD}_{5}$; spent emulsions; metalworking wastewater

\section{Introduction}

Synthetic lubricants are a complex mixture of chemical components including olefins, paraffins, naphthenes, aromatic hydrocarbons, etc. and show low biodegradability with release of harmful compounds into the environment [1-6]. Accordingly, the growing level of environmental awareness has resulted in major investment for the research and development of new nontoxic and biodegradable oils from vegetable and animal origin [7-10].

The vegetable lubricants show an amphiphilic structure based on long fatty acid chain and polar end groups and are characterized by low ecotoxicity and a high degree of biodegradability [2]. The fatty acids composition and consequently the physical properties of these lubricants are dependent from the plant species, the climatic conditions, the soil type and the genetic variations in the plant. Vegetable lubricants are based on sunflower, soybean, palm, corn, castor, cotton seed, rape seed, vernonia oils, etc. [11-13].

Animal lubricants are water insoluble and hydrophobic materials deriving from the animal fats (hard fats, i.e., stearin and soft fats, i.e., lard). The structure of these materials is based on glyceryl esters of fatty acids known as triglycerides [14,15]. The fatty acids composition and consequently the physical properties are dependent from the animal species and the living environment. In fact, the marine animal fats are different from those deriving from the land animals and the fatty acids 
composition is dependent from the animal species, the type of surface water (ocean or freshwater) and the environment (cold or warm water). Animal lubricants are based on beef fat, clove oil, fish oil, mink oil, etc. [10,16].

The vegetable and animal oils may be more expensive than the mineral lubricants but they can be surely considered alternative materials due to appropriate physico-chemical properties including good lubricity, high viscosity index, high flash point, relevant anticorrosion properties, high biodegradability and low toxicity $[10,17,18]$. Moreover, the supply of petroleum resources is limited, and the increased demand worldwide is difficult to assure, so the production of environmentally safe lubricants from renewable resources is increasing [11,13].

The current EU legislation, concerning lubricants applicable in the European Union (EU), has established the criteria and the requirements for the degree of biodegradability using standard tests which allow a degradation value of $60 \%$ for a period of 28 days [19]. The aim is to promote the use of eco-friendly and not harmful products for water and soil in order to guarantee the reduction of the impact on the aquatic environment and on the soil during use, the reduction of $\mathrm{CO} 2$ emissions, a high percentage of renewable raw materials, a reduced use of dangerous substances and high technical performances.

Commercial metalworking fluids, usually adopted for cutting and modeling operation of metal parts, are aqueous emulsions with an oil content generally in the range of $2 \%-10 \%$ [20]. In addition, they generally contain other compounds, such as emulsifiers, antiwear additives, biocides and corrosion inhibitors, used to increase the emulsion life, provide detergency and protect metal parts from corrosion [21]. During operations, emulsion is contaminated with hydraulic fluids, iron fines and scrap materials. Moreover, high local temperatures can cause thermal degradation [22]. Consequently, the emulsion loses its effectiveness over time and must be replaced. Even if diluted with other wastewater streams produced in the plant, according to the Italian regulation, spent emulsions cannot be discharged in the sewer due to the high COD content, which can reach $200 \mathrm{~g} / \mathrm{L}$ [23]. To overcome this problem, some physical [24-26] and physico-chemical [27-29] treatments are used with the aim to break the emulsion and separate the oily phase, thus allowing the discharge of the aqueous phase in the sewer and reducing the amount of waste to be disposed of. However, spent emulsion treatments entail high operating costs due to chemicals and/or energy consumption and require costly equipment that shall be operated by specialized personnel. As a result, many metalworking plants utilize specialized companies that deal with the collection, transportation and disposal of spent emulsion at a cost of $150-200 € / \mathrm{m} 3$.

The scope of this study is to assess the environmental impact of a new metalworking oil made from bio-based oil from renewable sources, specifically slaughtering waste.

\section{Materials and Methods}

\subsection{Materials}

COD, $\mathrm{BOD}_{5}$ and NIS analysis were carried out on $5 \% w / w$ emulsions prepared with the following metalworking oils: CSE-A, CSE-B and CADT-605 (supplied by Kimya Srl, Bari, Italy). COD is the chemical oxygen demand, i.e., the measure of the capacity of water to consume oxygen during the decomposition of organic matter and the oxidation of inorganic chemicals. $\mathrm{BOD}_{5}$ is the five day biochemical oxygen demand, i.e., the amount of oxygen consumed by bacteria and other microorganisms in a water sample during the period of 5 days at a temperature of $20^{\circ} \mathrm{C}$. NIS are the non-ionic surfactants which are molecules with no charged groups in its head. Unlike the vast majority of the products available in the market, CADT 605 is not available as neat oil but as a pre-emulsified oil consisting of $50 \%$ oil and $50 \%$ demineralized water. Therefore, a 10\% w/w emulsion of CADT 605 was prepared in order to have $5 \% w / w$ oil concentration.

All emulsions were prepared using tap water. Moreover, a sample of CADT 605 spent emulsion was analyzed to assess the impact of contaminants (mainly steel fines, hydraulic fluids and slideway 
oils) and oil degradation on the chemical parameters under investigation. CADT 605 spent emulsion was supplied by the Dana Incorporated plant of Bari (Strada Provinciale Modugno-Bari, 4, Bari, Italy), specialized in manufacturing carbon steel parts for the automotive industry. Dana plant normally uses CSE-A as emulsified metalworking oil. In order to test CADT 605 performance, an industrial trial was carried out from September 2018 until August 2019 on four machine tools.

The Sample of CADT 605 spent emulsion consisted of a blend 50:50 on volume basis of two samples taken after 30 days of operations ( $24 \mathrm{~h} / 6$ days per week) from a Quasar 7177 machining center used for hole drilling and Forst 6645 machine used for broach sharpening (Figure 1).

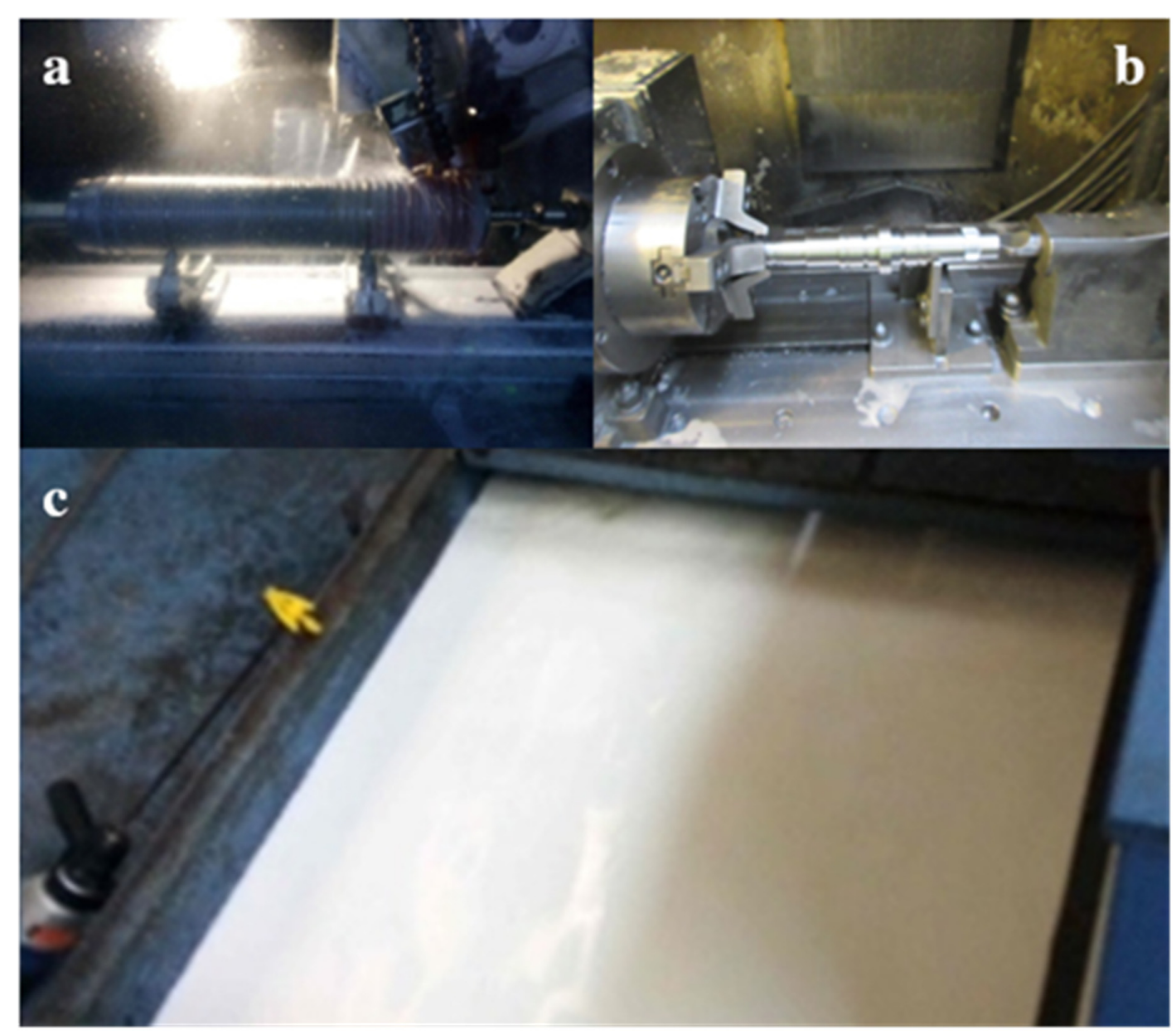

Figure 1. Forst 6645 sharpening machine (a), Quasar 7177 machining center (b) and CADT 605 emulsion collection tank (c).

Chemical parameters of the fresh emulsions and spent emulsion before emulsion breaking are included in Table 1.

Table 1. Chemical Oxygen Demand (COD), 5 day Biochemical Oxygen Demand (BOD 5 ) and Non-Ionic Surfactants (NIS) values of the $5 \% w / w$ fresh emulsions and spent emulsion.

\begin{tabular}{ccccc}
\hline Emulsion Type & $\begin{array}{c}\text { Oil Content }(\% \\
\boldsymbol{w} / \boldsymbol{w})\end{array}$ & COD (mg/L) & BOD $_{\mathbf{5}}(\mathbf{m g} / \mathbf{L})$ & NIS (mg/L) \\
\hline CSE-A & 5 & 85,000 & 4100 & 6000 \\
CSE-B & 5 & 128,600 & 9900 & 7500 \\
Kimya CADT 605 & 5 & 149,700 & 11,650 & $<0.2$ \\
Kimya CADT 605 & 5.8 & 212,653 & 43,350 & 74 \\
spent emulsion & & & & \\
\hline
\end{tabular}


Sulfuric acid (95\%-98\%) and Calcium Hydroxide ( $\geq 95 \%)$ used for emulsion breaking and $\mathrm{pH}$ neutralization were supplied by Sigma-Aldrich. In order not to alter the volume of the solution, $\mathrm{Ca}(\mathrm{OH})_{2}$ powder was used after drying at $105^{\circ} \mathrm{C}$.

In the case of COD, BOD5 and NIS analysis of samples out-of-range, dilutions were made with RPE Carlo Erba Water for Analysis.

All the reagents and the metalworking oils were used as received.

\subsection{Experimental Apparatus and Procedures}

The breaking of the fresh and spent emulsions was carried out in 200-mL glass separating funnels. In particular, $100 \mathrm{~mL}$ of emulsion were poured into the funnel. After adding different amounts of sulfuric acid, emulsion was left to rest for $24 \mathrm{~h}$ to allow separation of oily and aqueous phase. Three different doses of sulfuric acid were used to reach the following concentrations: 2,10 and $20 \mathrm{~mL} / \mathrm{L}$. After $24 \mathrm{~h}$, the aqueous phase was completely removed from the bottom of the separating funnel and transferred into a glass beaker where it was magnetically stirred to homogenize.

COD, NIS, $\mathrm{pH}$ and conductivity of the aqueous phase were evaluated after emulsion breaking.

$\mathrm{pH}$ neutralization was carried out by adding $\mathrm{Ca}(\mathrm{OH})_{2}$ to the aqueous phase recovered from bottom of the separating funnel. Aliquots of $100 \mathrm{mg}$ of dry $\mathrm{Ca}(\mathrm{OH})_{2}$ powder were added to the aqueous phase until $\mathrm{pH}$ was in the range 7.5-8.5. Finally, aqueous phase was filtered with paper to remove the $\mathrm{CaSO}_{4}$ precipitate and analyzed to quantify the $\mathrm{COD}, \mathrm{BOD}_{5}$ and NSI concentrations.

Each experimental run was carried out in triplicate to get more robust data.

\subsection{Analytical Methods}

$\mathrm{COD}, \mathrm{BOD}_{5}$ and NIS analysis were respectively carried out using Hach Lange LCK 514 cuvette (100-2000-mg/L O2), Hach Lange LCK 555 cuvette (4-1460-mg/L $\mathrm{O}_{2}$ ) and Hach Lange LCK 333 cuvette (0,2-6-mg/L Triton X-100) with pre-dosed reagents. Spectrophotometer Hach DR/3900 was used, as required by the experimental procedures of three colorimetric methods mentioned above. Proper dilution (1:10 and 1:100) with RPE Carlo Erba Water for Analysis was carried out on the samples with out of range $\mathrm{COD}, \mathrm{BOD}_{5}$ and NIS concentrations.

Conductivity and pH were measured by means of CDC40101 (Hach) and PHC10101 (Hach) electrodes, respectively. Aforementioned electrodes were connected to the benchtop meter HQ440d (Hach).

\section{Results}

\subsection{Chemical Parameters of the Fresh Emulsions}

The first part of the experimental campaign was focused on the analysis of $\mathrm{COD}, \mathrm{BOD}_{5}$ and NIS of the CSE-A, CSE-B and CADT 605 emulsions after the two steps chemical treatment: after emulsion breaking and $\mathrm{pH}$ neutralization. Figure 2a shows COD concentrations after emulsion breaking with sulfuric acid at three different concentrations, i.e., 2,10 and $20 \mathrm{~mL} / \mathrm{L}$.

It can be noticed that after the addition of only $2-\mathrm{mL} / \mathrm{L}$ sulfuric acid, the COD content of CADT 605 aqueous phase was reduced to only $1850 \mathrm{mg} / \mathrm{L}$, two orders of magnitude smaller than the initial one (refer to Table 1). The addition of $2-\mathrm{mL} / \mathrm{L}$ sulfuric acid to the CSE-A emulsion led to a $70 \%$ COD decrease in the aqueous phase, while no emulsion breaking was observed for CSE-B. Higher amounts of acid had to be added in order to observe CSE-B emulsion breaking.

Even with the addition of 20-mL/L sulfuric acid, the COD of CSE-A and CSE-B aqueous phases were both in the range of 15-20 g/L. As shown in Figure 2b, the addition of calcium hydroxide had a negligible effect on COD removal. 
a)

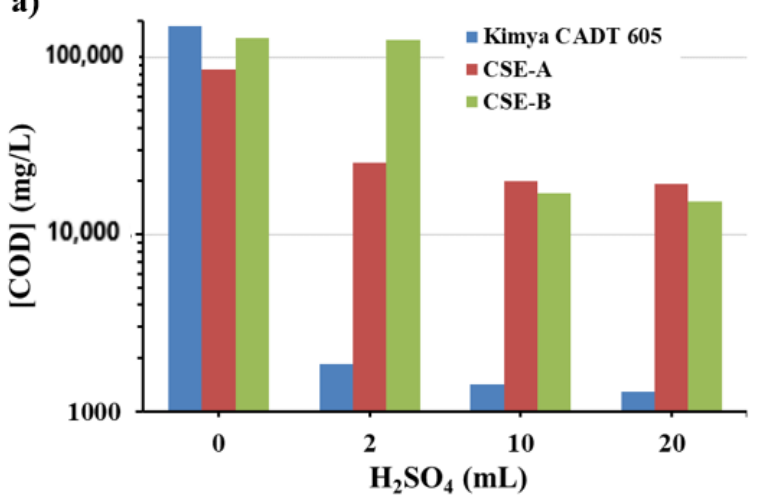

b)

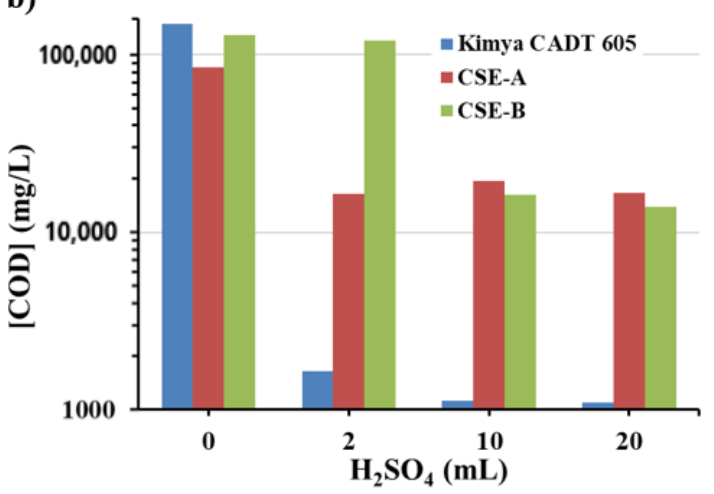

Figure 2. COD concentrations in the aqueous phases (a) after the addition of sulfuric acid and (b) after $\mathrm{pH}$ neutralization.

Figure 3a shows the BOD5 content after the two-step chemical treatment and is characterized by a similar COD trend. In particular, after addition of $2 \mathrm{~mL} / \mathrm{L}$ of sulfuric acid to CADT 605 emulsion, BOD5 content in the aqueous phase was lowered by $96.4 \%$, with a final concentration of $420 \mathrm{mg} / \mathrm{L}$. An increase in the sulfuric acid concentration up to $20 \mathrm{~mL} / \mathrm{L}$ resulted in a final $\mathrm{BOD}_{5}$ concentration of $214 \mathrm{mg} / \mathrm{L}$.
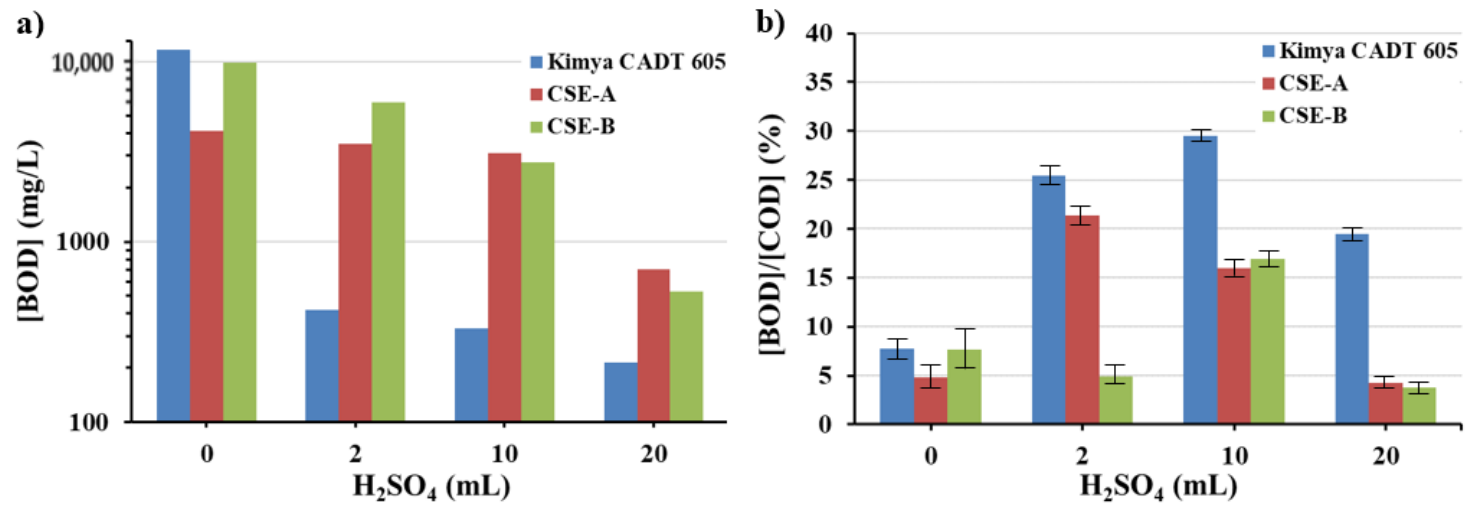

Figure 3. (a) $\mathrm{BOD}_{5}$ concentration and (b) BOD5/COD ratio in the aqueous phases after chemical treatment at increasing sulfuric acid concentrations.

The addition of 20-mL/L sulfuric acid to CSE-A and CSE-B emulsions resulted in a reduction of $\mathrm{BOD}_{5}$ in the aqueous phase of $83 \%$ and $95 \%$ respectively.

With regard to the $\mathrm{BOD}_{5} / \mathrm{COD}$ ratio, showed in Figure $3 \mathrm{~b}$, the higher value was obtained when 10-mL/L sulfuric acid were added to the CADT 605 emulsion, i.e., rapidly biodegradable compounds constituted almost $30 \%$ of the residual COD in the aqueous phase.

NIS content was absent in the CADT 605 emulsion (reference is made to Table 1), whereas no reduction was observed after the two-step chemical treatment carried out on CSE-A and CSE-B emulsions.

Conductivity of the aqueous phase after emulsion breaking was affected by the acid dose in all the cases, reaching the highest values $(127-148 \mathrm{mS} / \mathrm{cm})$ when $20-\mathrm{mL} / \mathrm{L}$ sulfuric acid were added. However, after the $\mathrm{pH}$ neutralization with calcium hydroxide, conductivity was lowered to $5-6 \mathrm{mS} / \mathrm{cm}$ due to the precipitation of calcium sulfate.

\subsection{Chemical Parameters of CADT 605 Spent Emulsion}

Chemical parameters of CATD 605 spent emulsion after emulsion breaking and $\mathrm{pH}$ neutralization are summarized in Table 1 . The COD content in the CADT 605 spent emulsion was $\sim 42 \%$ higher than 
the fresh one. The difference is mainly ascribed by the presence of contaminants (iron fines, hydraulic oil and slideway oil), higher concentration of oil (5.8\% vs. $5 \%$ ) and degradations processes.

In addition to a higher COD, the spent emulsion contained a NIS concentration of 74-mg/L (refer to Table 1) because, during the use of CADT-605 as emulsified metalworking oil, it was contaminated by other surfactant-containing hydraulic and slideway oils adopted by the equipment and which contributed to the release of non-ionic surfactants in the spent emulsion.

After emulsion breaking with 2-mL/L sulfuric acid (ref. Figure 4a), COD removal efficiency was approximately $65 \%$, a value much lower than the one observed for the fresh emulsion. This value is actually similar to the one obtained on CSE-A emulsion with the same amount of sulfuric acid.
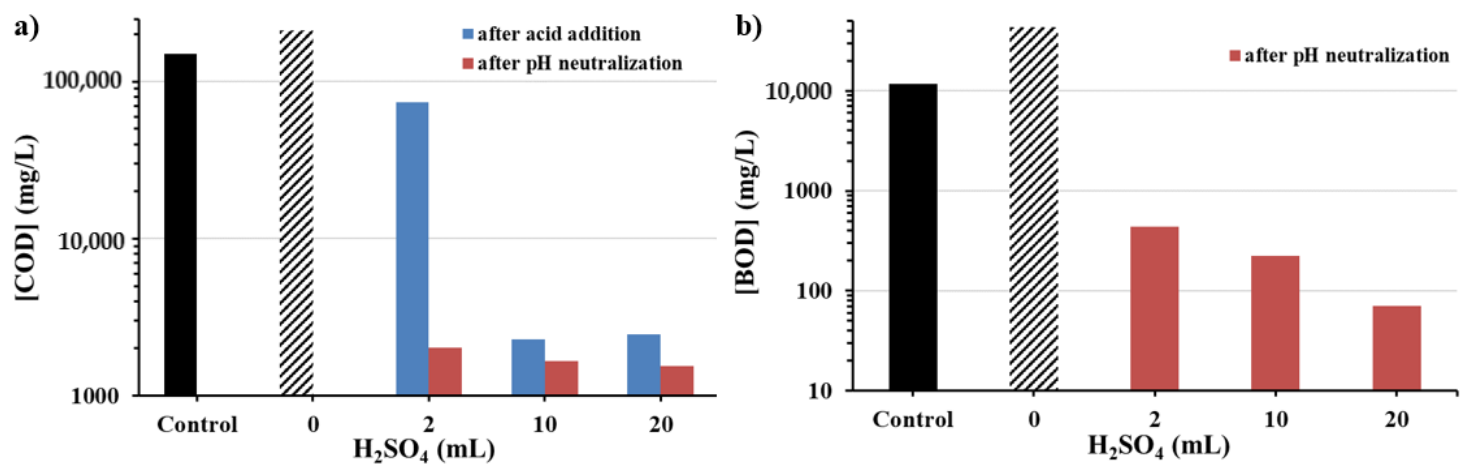

Figure 4. (a) COD concentration in the aqueous phases during the chemical treatment and (b) $\mathrm{BOD}_{5}$ concentration at the end of the treatment at increasing sulfuric acid concentrations.

The difference in COD removal efficiency between fresh and spent emulsion can be explained by the contamination of $\mathrm{Fe}(0)$ residues coming from the material being machined. In fact, the addition of low concentrations of sulfuric acid $(2 \mathrm{~mL} / \mathrm{L})$ to the spent emulsion resulted in a $\mathrm{pH}$ of approximately 4 , which was much higher than the value obtained on the fresh emulsion $(\mathrm{pH}<2)$. This can be explained by the acid consumed for the oxidation reaction of $\mathrm{Fe}(0)$ to $\mathrm{Fe}(\mathrm{II}) / \mathrm{Fe}(\mathrm{III})$ ions. Nevertheless, after $\mathrm{pH}$ neutralization with calcium hydroxide, COD was lowered to approximately 2000-mg/L because of the production of iron hydroxide which enhanced the efficiency of coagulation operated by lime [30,31]. However, although the COD concentration in the aqueous phase was finally lowered, the disposal of the precipitate characterized by a high content of organic compounds represents an additional cost item. Accordingly, a possible reuse of the precipitate, mainly constituted by calcium sulfate dehydrate (gypsum) with a small amount of organic compounds, as in the case of the precipitated obtained after the treatment carried out with $10-\mathrm{mL} / \mathrm{L}$ and $20-\mathrm{mL} / \mathrm{L}$ sulfuric acid (Figure $4 \mathrm{a}$ ), may be in the production of cement for the construction industry [32]. In fact, gypsum is an indispensable component due to role of retarding agent in controlling the rate of hardening of the hydraulic binders.

By increasing the acid dose to $10-\mathrm{mL} / \mathrm{L}$ and $20 \mathrm{~mL} / \mathrm{L}$, COD removal efficiencies similar to the ones obtained on the fresh emulsion were observed and, also in these cases, and the $\mathrm{pH}$ neutralization had only a small effect to the further decrease COD of the solution (Figure 4a).

After the two-step treatment of the spent emulsion, $\mathrm{BOD}_{5}$ (Figure $4 \mathrm{~b}$ ) in the aqueous phase was reduced by two orders of magnitude even with the addition of $2-\mathrm{mL} / \mathrm{L}$ sulfuric acid. Final $\mathrm{BOD}_{5}$ concentrations where in the range of $70-439 \mathrm{mg} / \mathrm{L}$.

With regard to the NIS, both the addition of sulfuric acid and $\mathrm{pH}$ neutralization had a positive effect on the surfactant removal. As shown in Figure $5 \mathrm{a}$, the addition of sulfuric acid resulted in a NIS reduction from $32 \%$ to $53 \%$, depending on the acid dosage. $\mathrm{pH}$ neutralization led to a further decrease of the NIS concentration, which reached the lowest value $(25 \mathrm{mg} / \mathrm{L})$ after treatment with $20-\mathrm{g} / \mathrm{L}$ sulfuric acid. Notably, the addition of the acid determined the degradation of the surfactant compounds with formation of products as carboxylic acid or alcohols, which contributed to the NIS reduction in the aqueous phase [33,34]. This result was more effective with the increase of the sulfuric acid dosage. 

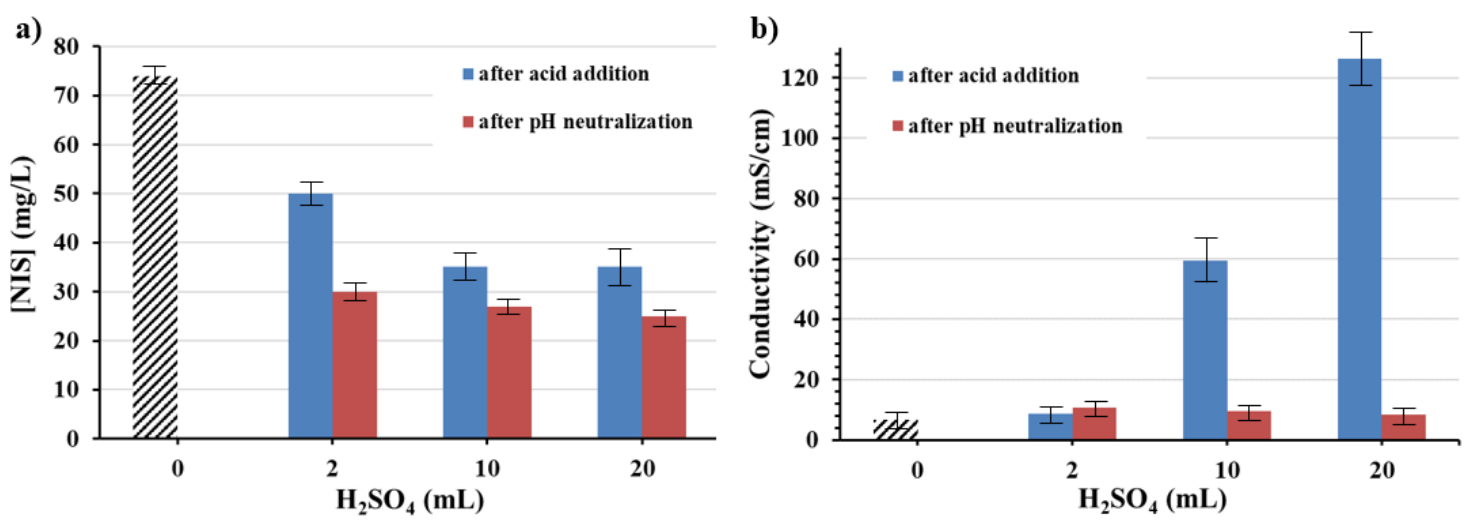

Figure 5. (a) NIS concentration and (b) conductivity in the aqueous phase after chemical treatment at increasing sulfuric acid concentrations.

Moreover, the $\mathrm{pH}$ neutralization by calcium hydroxide further affected the decrease of the NIS content due to the coagulation effect which induced the formation of the calcium sulfate precipitate. The surfactants present in this precipitate may be also reused as additives for air entrainment in lightweight concretes [35-38] or as co-surfactants because NIS have the advantage of good compatibility with all the other types of surfactants which are usually applied as additives for cement conglomerates $[39,40]$. Consequently, the cost of the precipitate disposal may be drastically reduced due to the recovery of a product (gypsum and NIS) which may be used as additive for the production of construction materials.

Conductivity of the aqueous phase, after treatment of the spent emulsion, never exceeded $8.6 \mathrm{mS} / \mathrm{cm}$, regardless of the acid concentration due to the precipitation of calcium sulfate, which could be easily removed from the bottom of the settling tank during the oil-water separation (Figure $5 b$ ).

The Italian regulation imposes very strict limits on the concentrations of pollutants to allow the discharge of industrial wastewater both in sewers and in surface water bodies [41]. As reported in Table 2, none of the treated spent solutions could be discharged both in sewers and in surface water bodies. However, a plant specialized in manufacturing steel parts generally discharges other types of wastewater deriving from many different activities and with different characteristics, which could be mixed with the treated exhaust emulsions. As example, Dana Incorporated plants generally discharges large amounts of water deriving from the cooling towers. In these plants almost $1.0 \mathrm{~m}^{3}$ spent emulsion are daily produced together with $20 \mathrm{~m}^{3}$ of water deriving from the cooling towers. Therefore, the treated exhausted emulsion could be discharged in both sewers and surface water bodies once they are diluted with the wastewater from the cooling towers (Table 2). In addition, the COD and $\mathrm{BOD}_{5}$ concentrations reported after the treatment of the spent emulsion and the dilution with water from cooling towers are lower than the limits imposed by most of the world regulations regarding the industrial wastewater discharge: $\mathrm{COD}<250 \mathrm{mg} / \mathrm{L}$ and $\mathrm{BOD}_{5}<30 \mathrm{mg} / \mathrm{L}$ [42].

Table 2. Comparison between the Italian limits on $\mathrm{COD}, \mathrm{BOD}_{5}$ and NIS content in industrial wastewater and their concentration in undiluted and diluted treated emulsion.

\begin{tabular}{|c|c|c|c|c|c|c|c|c|}
\hline & \multirow{2}{*}{$\begin{array}{l}\text { Limits for } \\
\text { Discharge in } \\
\text { Sewers }\end{array}$} & \multirow{2}{*}{$\begin{array}{l}\text { Limits for Discharge in } \\
\text { Surface Water Bodies }\end{array}$} & \multicolumn{3}{|c|}{ Undiluted Treated Emulsion } & \multicolumn{3}{|c|}{ Diluted Treated Emulsion } \\
\hline & & & $\begin{array}{c}2 \mathrm{~mL} \\
\mathrm{H}_{2} \mathrm{SO}_{4}\end{array}$ & $\begin{array}{r}10 \mathrm{~mL} \\
\mathrm{H}_{2} \mathrm{SO}_{4}\end{array}$ & $\begin{array}{r}20 \mathrm{~mL} \\
\mathrm{H}_{2} \mathrm{SO}_{4}\end{array}$ & $\begin{array}{c}2 \mathrm{~mL} \\
\mathrm{H}_{2} \mathrm{SO}_{4}\end{array}$ & $\begin{array}{l}10 \mathrm{~mL} \\
\mathrm{H}_{2} \mathrm{SO}_{4}\end{array}$ & $\begin{array}{l}20 \mathrm{~mL} \\
\mathrm{H}_{2} \mathrm{SO}_{4}\end{array}$ \\
\hline $\begin{array}{l}{[\mathrm{COD}]} \\
(\mathrm{mg} / \mathrm{L})\end{array}$ & 500 & 160 & 2043 & 1670 & 1545 & 102 & 84 & 77 \\
\hline $\begin{array}{c}{\left[\mathrm{BOD}_{5}\right]} \\
(\mathrm{mg} / \mathrm{L})\end{array}$ & 250 & 40 & 439 & 223 & 70 & 22 & 11 & 3.5 \\
\hline $\begin{array}{c}{[\mathrm{NIS}]} \\
(\mathrm{mg} / \mathrm{L})\end{array}$ & 4 & 2 & 30 & 27 & 25 & 1.5 & 1.35 & 1.25 \\
\hline
\end{tabular}


Specifically, the predicted $\mathrm{COD}, \mathrm{BOD}_{5}$, and NIS concentrations in diluted effluents highlight that it is possible to use $10 \mathrm{~mL} \mathrm{H}_{2} \mathrm{SO}_{4}$ to treat $1.0 \mathrm{~L}$ of emulsion. By considering that concentrated sulfuric acid $(98 \%)$ costs on average $300 € /$ ton - that is $0.55 € / L$ - the cost related to the sulfuric acid consumption for the treatment on $1.0 \mathrm{~m}^{3}$ exhausted emulsion is only $5.5 €$. In addition, the amount of calcium hydroxide added to neutralize the $\mathrm{pH}$ of the aqueous phase, after the addition of $10-\mathrm{mL} / \mathrm{L}$ sulfuric acid and the emulsion breaking, is only $1.4 \mathrm{~g} / \mathrm{L}$. Considering an average $\mathrm{Ca}(\mathrm{OH})_{2}$ cost of $220 € /$ ton, the cost related to the $\mathrm{pH}$ neutralization is only $0.32 € / \mathrm{m}^{3}$. Consequently, the cost related to reagent consumption to treat CADT 605 spent emulsion amounts to less than $5.82 € / \mathrm{m}^{3}$. Beyond the environmental benefits already mentioned in the introduction, the cost related to the treatment of these emulsions, compared with the costs required from specialized companies for the collection, the transportation, and the disposal of spent emulsions (a total of 150-200 $€ / \mathrm{m}^{3}$ ), should encourage metal working companies to adopt these new and eco-friendly emulsions in replacement of the synthetic cutting oils.

\section{Conclusions}

In this study, the environmental impact of a new metalworking bio-based oil deriving from renewable sources and named CADT 605 was analyzed and compared with two fresh commercial synthetic cutting oil emulsions (CSE-A and CSE-B).

The addition of 2-mL/L sulfuric acid to the fresh emulsions resulted in an emulsion braking only in the case of CADT 605 and CSE-A emulsions, while no emulsion breaking was observed for CSE-B. Specifically, more than $98 \%$ COD decrease was observed in the aqueous phase after the addition of only 2-mL/L sulfuric acid to the CADT 605 emulsion. In addition, $25 \%$ of the COD remaining in the aqueous phase was biodegradable in five days. On the opposite, COD removals of more than $90 \%$ were not achieved even after the addition of $20 \mathrm{~mL} / \mathrm{L}$ of sulfuric acid to the CSE-A and CSE-B emulsions, due to the high content of surfactants. The good results obtained after the physiochemical treatment of the CADT 605 emulsion were validated on a spent CADT 605 emulsion adopted in a metalworking plant within $30 \mathrm{~d}$. Even if during the cutting operations the emulsion was contaminated by hydraulic fluids and slideway oils, the proposed physiochemical treatment resulted in a good emulsion breaking and in a $>98 \%$ COD removal in the aqueous phase after the addition of $10 \mathrm{~mL} / \mathrm{L}$ or $20-\mathrm{mL} / \mathrm{L}$ sulfuric acid. The $\mathrm{pH}$ neutralization by calcium hydroxide led to a sufficient COD removal from the aqueous phase deriving from the emulsion breaking carried out with 2-mL/L sulfuric acid, but it would result in a more expensive precipitate disposal, due to the high organic content. However, the precipitated obtained after the treatment carried out with $10 \mathrm{~mL} / \mathrm{L}$ or $20-\mathrm{mL} / \mathrm{L}$ sulfuric acid may be used as additive for the production of construction materials.

Finally-regardless of the sulfuric acid amount used for the spent CADT 605 emulsion breaking the aqueous phase obtained at the end of the treatment-once mixed with other wastewater produced in the metalworking plant characterized by low-NIS content, it could be discharged both in sewers or in surface water bodies in agreement with the Italian regulation.

Author Contributions: Conceptualization, D.S.; Formal analysis, D.S. and A.P.; Investigation, D.S. and A.P.; Methodology, A.P.; Resources, V.L.; Visualization, V.L. All authors have read and agreed to the published version of the manuscript.

Funding: This research received no external funding.

Conflicts of Interest: The authors declare no conflict of interest.

\section{References}

1. Maisano, M.; Cappello, T.; Natalotto, A.; Vitale, V.; Parrino, V.; Giannetto, A.; Oliva, S.; Mancini, G.; Cappello, S.; Mauceri, A.; et al. Effects of petrochemical contamination on caged marine mussels using a multi-biomarker approach: Histological changes, neurotoxicity and hypoxic stress. Mar. Environ. Res. 2017, 128, 114-123. [CrossRef] [PubMed] 
2. Karmakar, G.; Ghosh, P.; Sharma, B.K. Chemically modifying vegetable oils to prepare green lubricants. Lubricants 2017, 5, 44. [CrossRef]

3. Nowak, P.; Kucharska, K.; Kamiński, M. Ecological and health effects of lubricant oils emitted into the environment. Int. J. Environ. Res. Public Health 2019, 16, 3002. [CrossRef]

4. Mancini, G.; Panzica, M.; Fino, D.; Cappello, S.; Yakimov, M.M.; Luciano, A. Feasibility of treating emulsified oily and salty wastewaters through coagulation and bio-regenerated GAC filtration. J. Environ. Manag. 2017, 203, 817-824. [CrossRef] [PubMed]

5. Viotti, P.; Di Palma, P.R.; Aulenta, F.; Luciano, A.; Mancini, G.; Papini, M.P. Use of a reactive transport model to describe reductive dechlorination (RD) as a remediation design tool: Application at a CAH-contaminated site. Environ. Sci. Pollut. Res. 2014, 21, 1514-1527. [CrossRef] [PubMed]

6. Luciano, A.; Mancini, G.; Torretta, V.; Viotti, P. An empirical model for the evaluation of the dissolution rate from a DNAPL-contaminated area. Environ. Sci. Pollut. Res. 2018, 25, 33992-34004. [CrossRef]

7. Ghosh, P.; Karmakar, G. Evaluation of sunflower oil as a multifunctional lubricating oil additive. Int. J. Ind. Chem. 2014, 5, 7. [CrossRef]

8. Ghosh, P.; Hoque, M.; Karmakar, G. Castor oil as potential multifunctional additive in the formulation of eco-friendly lubricant. Polym. Bull. 2018, 75, 501-514. [CrossRef]

9. Zainal, N.A.; Zulkifli, N.W.M.; Gulzar, M.; Masjuki, H.H. A review on the chemistry, production and technological potential of bio-based lubricants. Renew. Sustain. Energy Rev. 2018, 82, 80-102. [CrossRef]

10. Padgurskas, J.; Rukuiža, R.; Mandziuk, I.; Kupcinskas, A.; Prisyazhna, K.; Grigoriev, A.; Kavaliova, I.; Revo, S. Tribological properties of beef tallow as lubricating grease. Ind. Lubr. Tribol. 2017, 69, 645-654. [CrossRef]

11. Boyde, S. Green lubricants. Environmental benefits and impacts of lubrication. Green Chem. 2012, 4, $293-307$. [CrossRef]

12. Fox, N.J.; Stachowiak, G.W. Vegetable oil-based lubricants. A review for oxidation. Tribol. Int. 2007, 40, 1035-1046. [CrossRef]

13. Syahir, A.Z.; Zulkifli, N.W.M.; Masjuki, H.H.; Kalam, M.A.; Alabdulkarem, A.; Gulzar, M.; Khuong, L.S.; Harith, M.H. A review on bio-based lubricants and their applications. J. Clean. Prod. 2017, 168, 997-1016. [CrossRef]

14. Angulo, B.; Fraile, J.M.; Gil, L.; Herrerías, C.I. Bio-lubricants production from fish oil residue by transesterification with trimethylolpropane. J. Clean. Prod. 2018, 202, 81-87. [CrossRef]

15. Mandziuk, I.A.; Prisyazhna, K.O. Industrial lubricants based on renewable raw materials. Report 1 . Properties of the natural acylglycerols. J. Chem. Technol. 2015, 23, 32-37. [CrossRef]

16. do Valle, C.P.; Rodrigues, J.S.; Fechine, L.M.U.D.; Cunha, A.P.; Malveira, J.Q.; Luna, F.M.T.; Ricardo, N.M.P.S. Chemical modification of Tilapia oil for biolubricant applications. J. Clean. Prod. 2018, 191, 158-166. [CrossRef]

17. Salimon, J.; Salih, N.; Yousif, E. Biolubricants: Raw materials, chemical modifications and environmental benefits. Eur. J. Lipid Sci. Technol. 2010, 112, 519-530. [CrossRef]

18. Salimon, J.; Abdullah, B.M.; Yusop, R.M.; Salih, N. Synthesis, reactivity and application studies for different biolubricants. Chem. Cent. J. 2014, 8, 16. [CrossRef]

19. Council Regulation (EC). No 440/2008 Laying Down Test Methods Pursuant to Regulation (EC) No 1907/2006 of the European Parliament and of the Council on the Registration, Evaluation, Authorisation and Restriction of Chemicals (REACH); European Union: Brussels, Belgium, 2008.

20. Bensadok, K.; Belkacem, M.; Nezzal, G. Treatment of cutting oil/water emulsion by coupling coagulation and dissolved air flotation. Desalination 2007, 206, 440-448. [CrossRef]

21. Benito, J.M.; Cambiella, A.; Lobo, A.; Gutiérrez, G.; Coca, J.; Pazos, C. Formulation, characterization and treatment of metalworking oil-in-water emulsions. Clean Technol. Environ. 2010, 12, 31-41. [CrossRef]

22. Giannopoulos, D.; Kolaitis, D.I.; Togkalidou, A.; Skevis, G.; Founti, M.A. Quantification of emissions from the co-incineration of cutting oil emulsions in cement plants-Part I: NOx, CO and VOC. Fuel 2007, 86, 1144-1152. [CrossRef]

23. Soković, M.; Mijanović, K. Ecological aspects of the cutting fluids and its influence on quantifiable parameters of the cutting processes. J. Mater. Process. Technol. 2001, 109, 181-189. [CrossRef]

24. Vasanth, D.; Pugazhenthi, G.; Uppaluri, R. Cross-flow microfiltration of oil-in-water emulsions using low cost ceramic membranes. Desalination 2013, 320, 86-95. [CrossRef] 
25. Islam, M.S.; McCutcheon, J.R.; Rahaman, M.S. A high flux polyvinyl acetate-coated electrospun nylon 6/SiO 2 composite microfiltration membrane for the separation of oil-in-water emulsion with improved antifouling performance. J. Membr. Sci. 2017, 537, 297-309. [CrossRef]

26. Venault, A.; Chiang, C.H.; Chang, H.Y.; Hung, W.S.; Chang, Y. Graphene oxide/PVDF VIPS membranes for switchable, versatile and gravity-driven separation of oil and water. J. Membr. Sci. 2018, 565, 131-144. [CrossRef]

27. Karhu, M.; Leiviskä, T.; Tanskanen, J. Enhanced DAF in breaking up oil-in-water emulsions. Sep. Purif. Technol. 2014, 122, 231-241. [CrossRef]

28. Demirbas, E.; Kobya, M. Operating cost and treatment of metalworking fluid wastewater by chemical coagulation and electrocoagulation processes. Process. Saf. Environ. 2017, 105, 79-90. [CrossRef]

29. Amin, M.M.; Mofrad, M.M.G.; Pourzamani, H.; Sebaradar, S.M.; Ebrahim, K. Treatment of industrial wastewater contaminated with recalcitrant metal working fluids by the photo-Fenton process as post-treatment for DAF. J. Ind. Eng. Chem. 2017, 45, 412-420. [CrossRef]

30. Sykora, J.L.; Smith, E.J.; Synak, M. Effect of lime neutralized iron hydroxide suspensions on juvenile brook trout (Salvelinus fontinalis, Mitchill). Water Res. 1972, 6, 935-950. [CrossRef]

31. Tchobanoglous, G.; Burton, F.L.; Stensel, H.D. Wastewater Engineering: Treatment and Reuse; Metcalf \& Eddy Inc. McGraw-Hill: New York, NY, USA, 2003.

32. Suárez, S.; Roca, X.; Gasso, S. Product-specific life cycle assessment of recycled gypsum as a replacement for natural gypsum in ordinary Portland cement: Application to the Spanish context. J. Clean. Prod. 2016, 117, 150-159. [CrossRef]

33. Worm, M.; Kang, B.; Dingels, C.; Wurm, F.R.; Frey, H. Acid-labile amphiphilic PEO-b-PPO-b-PEO copolymers: Degradable poloxamer analogs. Macromol. Rapid Commun. 2016, 37, 775-780. [CrossRef] [PubMed]

34. Xiang, W.; Tardy, B.; Bai, L.; Stubenrauch, C.; Rojas, O.J. Measuring the interfacial behavior of sugar-based surfactants to link molecular structure and uses. In Biobased Surfactants Synthesis, Properties, and Applications, 2nd ed.; AOCS Press: Urbana, IL, USA, 2019; pp. 387-412.

35. Petrella, A.; Petrella, M.; Boghetich, G.; Petruzzelli, D.; Calabrese, D.; Stefanizzi, P.; De Napoli, D.; Guastamacchia, M. Recycled waste glass as aggregate for lightweight concrete. Proc. Inst. Civ. Eng. Constr. Mater. 2007, 160, 165-170. [CrossRef]

36. Petrella, A.; Petrella, M.; Boghetich, G.; Petruzzelli, D.; Ayr, U.; Stefanizzi, P.; Calabrese, D.; Pace, L.; Guastamacchia, M. Thermo-acoustic properties of cement-waste-glass mortars. Proc. Inst. Civ. Eng. Constr. Mater. 2009, 162, 67-72. [CrossRef]

37. Petrella, A.; Spasiano, D.; Rizzi, V.; Cosma, P.; Race, M.; De Vietro, N. Lead ion sorption by perlite and reuse of the exhausted material in the construction field. Appl. Sci. 2018, 8, 1882. [CrossRef]

38. Petrella, A.; Spasiano, D.; Liuzzi, S.; Ayr, U.; Cosma, P.; Rizzi, V.; Petrella, M.; Di Mundo, R. Use of cellulose fibers from wheat straw for sustainable cement mortars. J. Sustain. Cem. Based Mater. 2019, 8, 161-179. [CrossRef]

39. Aïtcin, P.C.; Flatt, R.J. Science and Technology of Concrete Admixtures; Woodhead Publishing: Cambridge, UK, 2015; pp. 195-218.

40. Feneuil, B.; Pitois, O.; Roussel, N. Effect of surfactants on the yield stress of cement paste. Cem. Concr. Res. 2017, 100, 32-39. [CrossRef]

41. Decreto Legislativo No 152/2006. In Norme in Materia Ambientale; Italian Parliament: Rome, Italy, 2006.

42. Ranade, V.V.; Bhandari, V.M. Industrial Wastewater Treatment, Recycling and Reuse; Butterworth-Heinemann, Elsevier: Oxford, UK, 2014.

(C) 2020 by the authors. Licensee MDPI, Basel, Switzerland. This article is an open access article distributed under the terms and conditions of the Creative Commons Attribution (CC BY) license (http://creativecommons.org/licenses/by/4.0/). 